\title{
Adaptação transcultural e validação do instrumento Parental Health Literacy Activities Test (PHLAT)
}

\author{
Transcultural adaptation and validation of the instrument Parental \\ Health Literacy Activities Test (PHLAT)
}

Francielle Brustolin de Lima Simch', Claudia Silveira Viera', Mauricio Bedim dos Santos ${ }^{\mathbf{2}}$, Beatriz Rosana Gonçalves de Oliveira Toso'

DOI: $10.1590 / 0103-1104202012704$

RESUMO O objetivo do estudo foi realizar a tradução, a adaptação cultural e a validação psicométrica do instrumento Parental Health Literacy Activities Test (PHLAT), que avalia o letramento em saúde para cuidadores/familiares que buscam atendimento às suas crianças menores de 1 ano na unidade de atenção primária. Estudo metodológico, quantitativo, de validação e adaptação transcultural de instrumento, seguindo as etapas de tradução, retrotradução, análise por comitê de juízes, aplicação de testes estatísticos para avaliação das propriedades psicométricas, obtendo-se sua versão para o português do Brasil. O pré-teste foi realizado com 31 familiares, e o teste/reteste, com 93, em unidades de atenção primária do município do Oeste do Paraná, em 2018 e 2019. Análise estatística inferencial foi aplicada para verificar a validade e a confiabilidade do instrumento. Na validade de conteúdo com comitê de juízes, obteve-se taxa de concordância de $100 \%$. Os dados na fase de pré-teste apresentaram coeficiente Alfa de Cronbach de 0,73; e na etapa do teste/reteste, obteve-se 0,69. A avaliação da confiabilidade pelo coeficiente de correlação intraclasse foi de 0,865 , considerada substancial. O instrumento foi tido como adequado quanto a sua adaptação cultural e validado para o português do Brasil, confiável para a aplicação entre cuidadores/familiares.

PALAVRAS-CHAVE Estudos de validação. Criança. Cuidadores. Saúde. Alfabetização.

1 Universidade Estadual do Oeste do Paraná (Unioeste) - Cascavel (PR), Brasil.

fbdlima@gmail.com

2 Universidade Federal do Paraná (UFPR) - Toledo (PR), Brasil.

\begin{abstract}
The purpose of the study was to perform the translation, cultural adaptation and psychometric validation of the instrument Parental Health Literacy Activities Test (PHLAT), which assesses health literacy for caregivers/family members seeking care for their children under one year old in the primary care unit. Methodological, quantitative, validation and cross-cultural instrument adaptation study, following the steps of translation, back-translation, judges committee analysis, application of statistical tests to evaluate psychometric properties, obtaining its version for Brazilian Portuguese. The pre-test was performed with 31 family members and test/retest with 93, in primary care units in the municipality of Western Paraná, in 2018 and 2019. Inferential statistical analysis was applied to verify the validity and reliability of the instrument. On the content validity of the judges committee, a 100\% agreement rate was obtained. The data in the pretest phase presented Cronbach's alpha coefficient of 0.73 , and the test/retest of 0.69 . The reliability assessment by the intraclass correlation coefficient was 0.865 , considered substantial. The instrument was considered adequate for its cultural adaptation and validated for Brazilian Portuguese, reliable for application between caregivers/family members.
\end{abstract}

KEYWORDS Validation studies. Child. Caregivers. Health. Literacy. 


\section{Introdução}

O letramento é resultante do processo de aprender a ler e a escrever, sendo a situação que um sujeito ou uma coletividade alcança após a apropriação da escrita e de suas práticas na sociedade. De outro modo, o letramento funcional se define por meio dos conhecimentos e habilidades de leitura e escrita que proporcionam ao indivíduo o envolvimento nas atividades distintas da sua área de abrangência'.

O Letramento Funcional em Saúde (LFS), que abrange o conhecimento, pode ser descrito como o estímulo e as capacidades individuais para acessar, assimilar, analisar e empregar as informações de saúde com a finalidade de exercer julgamentos e tomada de decisões, no que se refere à vida cotidiana a respeito de saúde, agravos, prevenção de doenças e promoção da saúde ${ }^{2}$.

Frequentemente, as informações são expressas de forma complexa, utilizando-se de terminologias médicas ou vocabulário formal que implicam a compreensão e, portanto, também a qualidade do cuidado ${ }^{3}$. O estresse resultante do diagnóstico de uma doença grave e a quantidade demasiada de informações médicas a serem seguidas colaboram para o Letramento em Saúde (LS) inadequado, bem como para o desencadeamento de desfechos clínicos negativos ${ }^{4}$. Neste estudo, os dois conceitos de LS e LFS foram considerados sinônimos.

Desta forma, o LS, devido a sua complexidade, multidimensionalidade, interdisciplinaridade ${ }^{5,6}$ e ao impacto que um inadequado letramento pode ocasionar para os indivíduos, família, comunidade e ao sistema de saúde, originou interesse no tema por parte de pesquisadores, profissionais de saúde e formuladores de políticas públicas?.

Em estudo de revisão de literatura sobre instrumentos e métodos de avaliação do LS, autores $^{8}$ identificaram 36 instrumentos de avaliação do LS, sendo os mais utilizados o Test of Functional Health Literacy in Adults (TOFHLA) - elaborado de forma a avaliar o nível de entendimento dos pacientes perante a comunicação existente na área médica, como receitas médicas, instruções para exames do público adulto em geral ${ }^{9}$ - e o Rapid Estimate of Adult Literacy in Medicine (REALM) instrumento de triagem desenvolvido para ser utilizado em ambientes de saúde pública e de cuidados primários com a finalidade de identificar pacientes com baixo nível de leitura ${ }^{10}$. Destaca-se o fato de a maior parte das pesquisas de validação de instrumentos, com a finalidade de avaliação do LS, serem constituídas por traduções e adaptações desses dois instrumentos ${ }^{8,11}$, o que ocorre nos estudos também no Brasil. No entanto, instrumentos que avaliem o LS para a realidade brasileira ainda são limitados.

O instrumento S-TOFHLA, uma versão reduzida do TOFHLA ${ }^{\mathbf{1 2}}$, teve sua tradução e sua validação realizadas ${ }^{13}$, a qual engloba 36 itens de leitura e 4 itens de habilidades numéricas ${ }^{\mathbf{1 2}}$. $\mathrm{O}$ instrumento Short Assessment of Health Literacy for Portuguese - Speaking Adults (SAHLPA) avalia o LS de indivíduos adultos, elaborado com base na tradução e adaptação de um instrumento espanhol intitulado SAHLSA ${ }^{11}$. Adaptado culturalmente e validado no Brasil14, o instrumento para pesquisa em promoção da saúde avaliou o nível de LS de universitários de diversos cursos de graduação. Recentemente, foi validado ${ }^{15} \mathrm{o}$ Teste de Letramento em Saúde (TLS), instrumento de avaliação do LS para a língua portuguesa do Brasil, resultante do processo de adaptação transcultural do TOFHLA.

O Teste de Atividades de Alfabetização em Saúde Parental (Parental Health Literacy Activities Test - PHLAT) é uma escala que investiga as habilidades de alfabetização em saúde e compreensão numérica (numeramento - terminologia utilizada para letramento numérico) de cuidadores infantis de bebês até 1 ano de idade. Os itens da escala testam tarefas comuns relacionadas com alfabetização e numeramento de cuidados realizados pelos pais de crianças menores de 1 ano. Isso inclui misturar fórmula de leite infantil, compreensão das 
recomendações sobre amamentação, quando e quanto dar de medicamentos pediátricos para tosse ou resfriado, por exemplo, por conta própria, sem receita médica (OTC - Over-TheCounter, denominação em inglês), assim como a compreensão da própria receita, quando uma medicação é prescrita pelo médico, e o entendimento de rótulos nutricionais ${ }^{16}$.

Como lacuna na avaliação em LS no País, perceberam-se instrumentos que o mensurem para o público infantil em relação ao conhecimento da família sobre os cuidados de saúde orientados por profissionais às crianças sob cuidados médicos. Assim, este estudo teve como objetivo a tradução, a adaptação cultural e a validação psicométrica do instrumento PHLAT para cuidadores/familiares de crianças de até 1 ano de idade que buscam atendimento na unidade de atenção primária.

\section{Material e métodos}

Este estudo foi aprovado pelo Comitê de Ética em Pesquisa com seres humanos da Universidade Estadual do Oeste do Paraná, regido pelas resoluções CNS 466/2012 e CNS $510 / 15$, sob o parecer de $n^{0} 2.787 .988$ e CAAE 93750118.0.0000.0107.

Para a adaptação transcultural e validação do instrumento PHLAT, o qual visa à obtenção de informações acerca do nível de LFS de cuidadores/familiares de crianças, foi obtida autorização antecipadamente dos autores do instrumento original.

O teste contém 20 questões, distribuídas em domínios clínicos, conforme segue: nutrição (1-3, 12, 17-20); psicossocial/desenvolvimento (6); acidentes/segurança $(4,5)$; e clínica/avaliações/imunização (7-10, 13-16). Em relação às habilidades predominantemente avaliadas, as questões estão assim distribuídas: letramento impresso $(1,5,12,13,14,15,19,20)$; adição e subtração (2); multiplicação e divisão (3, 17); frações e decimais $(4,10,16)$; múltiplas funções matemáticas $(8,18)$; e numeração, contas, hierarquia e gráficos $(6,7,9,11)$. Para a aplicação da escala, demonstram-se em cada item os gráficos ou figuras correspondentes à pergunta; e então as respostas são registradas no formulário, seguindo-se a codificação um quando a resposta está correta e zero quando está incorreta.

A validação seguiu as recomendações para o processo de adaptação transcultural de Beaton, Bombardier e Guillemin ${ }^{17}$, e as orientações para avaliar as propriedades psicométricas de instrumentos, quanto à confiabilidade e à validade, de Souza, Alexandre e Guirardello ${ }^{18}$ e Pernambuco et al. ${ }^{19}$.

O processo de Tradução, Adaptação Cultural e Validação (TACV), de acordo com os autores mencionados, seguiu as seguintes etapas:

a) adaptação cultural: tradução direta, síntese, tradução inversa, consolidação por comitê de experts e pré-teste.

b) validação: evolução da consistência interna, confiabilidade intraobservacional e/ ou interobservacional, validade aparente ou lógica, de conteúdo, critério e constructo.

\section{Tradução e a adaptação cultural}

A primeira etapa compreendeu a tradução e a adaptação cultural. Realizou-se a tradução conceitual do inglês para o português por dois tradutores bilíngues independentes, em que um tradutor tinha conhecimento prévio do instrumento e o outro não o possuía. Em seguida, verificou-se a síntese das traduções pelos tradutores, prosseguindo-se com a retrotradução ou tradução reversa do instrumento para a língua original, por dois especialistas na língua inglesa, elaborando-se a versão síntese da escala traduzida.

Para a continuidade do processo de adaptação cultural, foi constituído um comitê multidisciplinar com nove especialistas, sendo três profissionais em saúde infantil (médico pediatra, enfermeiro pediatra, enfermeiro neonatologista), um professor de metodologia, dois pesquisadores, um linguista e os dois tradutores, com objetivo de analisar as discrepâncias e obter a versão para o teste de 
campo. Nessa etapa, foi observada a equivalência semântica, idiomática, conceitual e cultural por meio das comparações entre as traduções e a adaptação cultural, sendo necessário adaptação de itens na língua portuguesa, que não eram adequados para a realidade brasileira. $\mathrm{O}$ instrumento com as adaptações realizadas obteve $100 \%$ de concordância, sendo denominado versão pré-teste.

\section{Pré-teste (aplicabilidade/ viabilidade)}

O alcance da fase final da adaptação cultural sucedeu-se com a aplicação da versão pré-teste. Essa etapa do processo buscou aplicar o teste de campo do instrumento, com uma amostra da população, para a verificação da aplicabilidade e viabilidade do instrumento. A versão pré-teste foi aplicada no período de outubro a dezembro de 2018, para validação do conteúdo, a 31 cuidadores/familiares de crianças de até 1 ano de idade nas unidades de atenção primária de um município do Oeste do Paraná. O cálculo amostral foi baseado no número de atendimentos de crianças menores de 1 ano no município do estudo para todas as etapas da pesquisa. O preenchimento do instrumento foi na forma autoaplicável, seguindo a recomendação do autor da escala original.

No momento da realização do preenchimento de cada escala, foi realizado um relatório sobre as dificuldades encontradas por meio da observação e aquelas relatadas pelos participantes. As questões consideradas com problemas, conforme descritas no relatório, foram revistas, sendo: questão 3 - intepretação quanto à análise do envelope de soro em pó, o qual foi substituído pelo rótulo de soro líquido; questão 14 - pois 14 dos 31 participantes dessa fase apontaram mais de uma alternativa de resposta na questão, indicando dupla interpretação. Dessa forma, o item febre foi acrescido de dor, conforme escrito na caixa do medicamento, na indicação de seu uso, permanecendo na opção c) febre/ dor. Efetuaram-se as adaptações da versão pré-teste para a aplicação da próxima etapa. Nessa etapa, realizou-se o coeficiente Alfa de Cronbach para avaliação da escala.

\section{Teste e reteste (confiabilidade do instrumento)}

Na sequência, realizou-se a investigação da confiabilidade da escala PHLAT, por meio do teste-reteste e a análise de consistência interna e das dimensões encontradas. Nessa etapa, participaram 93 cuidadores/familiares de crianças de até 1 ano de idade, nas unidades de atenção primária, não acompanhada de caracterização sociodemográfica. A aplicação do teste-reteste ocorreu no período de março a junho de 2019 e teve por finalidade a verificação da reprodutibilidade da escala traduzida e adaptada, possibilitando a visualização de sua estabilidade ao longo do tempo.

A aplicabilidade do instrumento e sua reaplicação ocorreram com um intervalo de 24 horas até 48 horas, sendo realizadas com os mesmos participantes, porém, o teste ocorreu nas unidades de saúde; enquanto o reteste, em domicílio. As questões da escala tiveram sua ordem modificada para que suas respostas não apresentassem influência da memória recente.

A avaliação da confiabilidade do instrumento foi verificada pelo Coeficiente de Correlação Intraclasse (CCI), entre os resultados do teste e reteste, avaliando a reprodutibilidade da escala. A consistência interna dos dados foi avaliada por meio da aplicação do coeficiente Alfa de Cronbach.

\section{Resultados}

Os dados no pré-teste indicaram coeficiente Alfa de Cronbach de 0,73 em intervalo de confiança de $95 \%$, conforme tabela 1 , sendo a versão de pré-teste aprovada para realização da próxima etapa, de teste-reteste. 
Tabela 1. Coeficiente Alfa de Cronbach das questões da PHLAT, no pré-teste, 2019

\begin{tabular}{|c|c|c|c|c|c|c|c|}
\hline & Valores de & Alpha & & Média correlação & & & \\
\hline Questões & alpha & padronizado & G6* & interitens & Erro padrão & Variância & Mediana \\
\hline Questão1.1 & 0.71 & 0.70 & 0.90 & 0.096 & 0.073 & 0.038 & 0.096 \\
\hline Questão 2 & 0.70 & 0.70 & 0.90 & 0.096 & 0.074 & 0.039 & 0.099 \\
\hline Questão 2.1 & 0.72 & 0.72 & 0.91 & 0.104 & 0.071 & 0.038 & 0.100 \\
\hline Questão 2.2 & 0.72 & 0.72 & 0.91 & 0.106 & 0.070 & 0.039 & 0.115 \\
\hline Questão 3.1 & 0.70 & 0.71 & 0.91 & 0.100 & 0.075 & 0.040 & 0.100 \\
\hline Questão 3.2 & 0.71 & 0.71 & 0.91 & 0.101 & 0.073 & 0.042 & 0.095 \\
\hline Questão 3.3 & 0.69 & 0.70 & 0.90 & 0.096 & 0.078 & 0.039 & 0.099 \\
\hline Questão 4 & 0.71 & 0.71 & 0.91 & 0.102 & 0.072 & 0.042 & 0.100 \\
\hline Questão 5 & 0.72 & 0.72 & 0.92 & 0.105 & 0.070 & 0.043 & 0.100 \\
\hline Questão 6 & 0.72 & 0.72 & 0.91 & 0.104 & 0.070 & 0.043 & 0.101 \\
\hline Questão 7 & 0.74 & 0.74 & 0.91 & 0.113 & 0.065 & 0.041 & 0.114 \\
\hline Questão 8 & 0.72 & 0.71 & 0.91 & 0.102 & 0.070 & 0.041 & 0.099 \\
\hline Questão 9 & 0.73 & 0.74 & 0.92 & 0.113 & 0.067 & 0.042 & 0.116 \\
\hline Questão 10 & 0.72 & 0.72 & 0.91 & 0.105 & 0.071 & 0.040 & 0.100 \\
\hline Questão 11 & 0.69 & 0.70 & 0.90 & 0.097 & 0.078 & 0.040 & 0.096 \\
\hline Questão 12 & 0.73 & 0.73 & 0.92 & 0.110 & 0.068 & 0.043 & 0.115 \\
\hline Questão 13 & 0.73 & 0.73 & 0.92 & 0.111 & 0.067 & 0.041 & 0.101 \\
\hline Questão 14 & 0.73 & 0.74 & 0.92 & 0.115 & 0.068 & 0.042 & 0.115 \\
\hline Questão 15 & 0.73 & 0.73 & 0.92 & 0.112 & 0.067 & 0.042 & 0.115 \\
\hline Questão 16 & 0.73 & 0.74 & 0.92 & 0.115 & 0.067 & 0.040 & 0.115 \\
\hline Questão 18 & 0.75 & 0.74 & 0.91 & 0.115 & 0.063 & 0.040 & 0.115 \\
\hline Questão 19 & 0.71 & 0.70 & 0.90 & 0.095 & 0.071 & 0.039 & 0.099 \\
\hline Questão 20 & 0.71 & 0.71 & 0.92 & 0.101 & 0.071 & 0.042 & 0.099 \\
\hline
\end{tabular}

Fonte: Elaboração própria.

${ }^{\star}$ G6 - Guttmans Lambda 6 teste de confiabilidade.

Na tabela 2, apresenta-se o percentual de acertos das respostas de acordo com cada questão.

Tabela 2. Apresentação do índice de acertos e erros das respostas de cada questão da PHLAT, no pré-teste, 2019

\begin{tabular}{lcc}
\hline & \multicolumn{2}{c}{ Respostas } \\
\cline { 2 - 2 } Questões & Incorretas & Corretas \\
\hline $\mathbf{1}$ Usando as instruções oferecidas na embalagem de leite em pó 1, quanto de água e de pó & \\
você deve colocar para fazer $\mathbf{1 2 0} \mathbf{m l}$ de leite? & $13 \%$ & $87 \%$ \\
1.1 Quantidade água utilizada: & $16 \%$ & $84 \%$ \\
\hline 1.2 Número de medidas colocadas: & \\
\hline $\mathbf{2}$ Usando as instruções oferecidas na embalagem de leite em pó 2, quanto de água e de pó \\
você colocaria para fazer $\mathbf{2 1 0}$ ml de leite? & $19 \%$ \\
2.1 Quantidade de água utilizada: & $81 \%$ \\
2.2 Número de medidas colocadas: & $10 \%$ & $90 \%$ \\
\hline
\end{tabular}


Tabela 2. (cont.)

Respostas

Questões

Incorretas Corretas

3 Seu bebê tem diarreia, e o pediatra recomenda que você dê uma mamadeira de $240 \mathrm{ml}$, misturando metade de leite e metade de soro para reidratação oral. Como você prepararia essa mamadeira com o leite em pó 1 ?

3.1 Quantidade de água utilizada:

3.2 Número de medidas colocadas:

3.3 Quantidade de soro utilizada:

$45 \% \quad 55 \%$

4 Você é informado pelo pediatra do seu bebê para levá-lo a um serviço de saúde se ele tiver uma temperatura de $38^{\circ} \mathrm{C}$ ou maior. No termômetro, está marcando a seguinte temperatura: $37,8^{\circ} \mathrm{C}$.

Você deveria levar sua criança para avaliação no serviço de saúde?

5 Vamos dizer que sua criança de 10 meses pesa 10.400 gramas e tem altura normal para a idade. Usando a tabela sobre o uso de assentos para crianças, qual assento para o carro você deve escolher para seu filho?
a) Bebê conforto, virado para trás, no banco traseiro
b) Bebê conforto, virado para a frente, no banco traseiro
C) Cadeira de segurança, virada para trás, no banco traseiro
d) Cadeira de segurança, virada para a frente, no banco traseiro

$0 \% \quad 0 \%$

$6 \mathrm{Na}$ consulta de acompanhamento de 2 meses do seu bebê, o médico lhe diz que, de acordo com a curva de crescimento infantil, ele está no percentil 25 de peso. 0 que esse percentil significa? Por favor, veja a curva de crescimento exibida.

7 Se seu bebê de 7 meses pesa 8 quilos e está com febre, quanto remédio para febre você deve dar a ele? Usando a Tabela de Dosagem do medicamento exibida, indique a quantidade de gotas de remédio que você deve dar ao seu filho. Decida a dose com base no peso dele.

8 Examinando as bulas dos dois tipos de medicamentos infantis para febre exibidas, de qual deles você precisaria usar um número menor de gotas, para tratar a febre do seu bebê?
a) Ibuprofeno $50 \mathrm{mg}$
$0 \%$
b) Ibuprofeno $100 \mathrm{mg}$

9 Seu bebê de 3 meses pesa 5 quilos e está com febre e você compra remédio para febre, em gotas. Usando a caixa como referência, você daria o medicamento ao seu bebê?

\begin{tabular}{lrl} 
( ) $\operatorname{Sim}$ & $94 \%$ & $6 \%$ \\
( ) Eu ligaria para o pediatra ou levaria ao serviço de saúde & $0 \%$ & $0 \%$ \\
( ) Não & $0 \%$ & $0 \%$ \\
\hline
\end{tabular}

10 Se você estiver usando remédio infantil para tratar a febre do seu filho, e seu médico recomendar que você dê apenas $1 / 2$ colher de chá do medicamento, quantos mililitros (ml) você precisa dar? Você pode consultar a tabela exibida.

11 Seu sobrinho de 3 anos e 16 quilos vem visitá-los e, de repente, ele está com febre. Para tratá-la, você decide dar-lhe o recomendado na bula do remédio infantil para febre de 2,5 $\mathrm{ml}$. Quanto você deve dar a ele?
a) $1 / 2$ colher de chá
b) 1 colher de chá
c) $1 \frac{1}{2}$ colher de chá

0\% $\quad 0 \%$
d) 1 colher de sopa

$0 \% \quad 0 \%$


Tabela 2. (cont.)

\begin{tabular}{|c|c|c|c|}
\hline \multirow[b]{2}{*}{ Questões } & & \multicolumn{2}{|c|}{ Respostas } \\
\hline & & Incorretas & Corretas \\
\hline \multicolumn{4}{|c|}{120 seu médico lhe dá a seguinte lista de alimentos para evitar dar ao seu bebê: } \\
\hline - Leite & - Amenc & & \\
\hline - Claras de ovos & - Peixe e & & \\
\hline - Uvas & - Cenour & & \\
\hline - Pipoca & - Cachor & & \\
\hline \multicolumn{4}{|c|}{$\begin{array}{l}\text { Depois de ler a lista de ingredientes do biscoito entregue, você daria isso para o seu bebê } \\
\text { de } 10 \text { meses? }\end{array}$} \\
\hline ( ) $\operatorname{Sim}$ & & $0 \%$ & $0 \%$ \\
\hline ( ) Não & & $26 \%$ & $74 \%$ \\
\hline \multicolumn{4}{|c|}{$\begin{array}{l}13 \text { Aos } 6 \text { meses de idade, seu bebê tem uma chance maior de pegar resfriados e outras } \\
\text { infecções. Tomando como exemplo o paracetamol gotas entregue, decida se você usaria } \\
\text { esse medicamento para seu filho e quanto você daria. }\end{array}$} \\
\hline ( ) Sim - eu daria & ade) & $0 \%$ & $0 \%$ \\
\hline ( ) Sim-mas eu & neiro & $39 \%$ & $61 \%$ \\
\hline ( ) Não - eu não c & meu filho & $0 \%$ & $0 \%$ \\
\hline \multicolumn{4}{|c|}{$\begin{array}{l}14 \text { De acordo com as informações na caixa do medicamento oferecida, que sintomas esta } \\
\text { medicação NÃO ajuda a aliviar. }\end{array}$} \\
\hline a) congestão nasa & & $0 \%$ & $0 \%$ \\
\hline b) Vômito & & $0 \%$ & $0 \%$ \\
\hline c) Febre & & $3 \%$ & $97 \%$ \\
\hline d) Tosse & & $0 \%$ & $0 \%$ \\
\hline
\end{tabular}

15 Seu bebê tem 1 ano de idade, pesa 8 quilos e está resfriado e com febre. Você dá a ele a quantidade de gotas de paracetamol que sempre usa, mas, uma hora depois, ele ainda está com febre. Você também tem um frasco de dipirona. $O$ que você deve fazer, dar o outro medicamento ou esperar?
a) Dar
$\mathrm{ml} /$ gotas de dipirona
$0 \%$
$0 \%$
b) Esperar, porque
$16 \% \quad 84 \%$

16 Seu bebê tem uma infecção no ouvido, e o médico receitou amoxicilina 3 vezes ao dia (ver frasco). Usando a seringa/copo, demonstre como você administraria a dose prescrita de $5 \mathrm{ml}$.

17 Um nutricionista diz-Ihe para dar ao seu bebê, com mais de 6 meses, não mais que $50 \mathrm{ml}$ de suco por vez. $200 \mathrm{ml}$ de suco dará para quantas vezes?

18 Bebidas industrializadas adoçadas possuem quantidades elevadas de açúcar e baixo teor de nutrientes importantes para manutenção da saúde. Deve-se dar preferência a sucos naturais com $100 \%$ de frutas ou vegetais. Os sucos prontos devem especificar no rótulo quanto de açúcar, vitaminas, proteínas, sódio e outros componentes contém. Com base nessa informação, analise o rótulo com os Dados Nutricionais, do suco demonstrado, e decida se poderia ser dado ao seu filho?

( ) $\operatorname{sim}$

19 Nos primeiros 3 dias de aleitamento materno, o peito fica inchado e dolorido. De acordo com este folheto, quanto tempo vai levar para melhorar?

$3 \% \quad 97 \%$


Tabela 2. (cont.)

\begin{tabular}{lcr}
\hline & \multicolumn{2}{c}{ Respostas } \\
\cline { 2 - 3 } Questões & Incorretas & Corretas \\
\hline 20 Você não tem certeza se o seu bebê está recebendo leite suficiente, uma vez que demora & & \\
cerca de 15 minutos para se alimentar em ambos os seios. De acordo com este folheto, isto é: & \\
a) normal & $10 \%$ & $90 \%$ \\
b) mais que o normal & $0 \%$ & $0 \%$ \\
c) menos que o normal & $0 \%$ & $0 \%$ \\
\hline
\end{tabular}

Fonte: Elaboração própria.

No pré-teste, as questões que apresentaram o percentual de acertos das respostas que ficaram em torno ou abaixo de $50 \%$ foram as 3.1, 3.3, 18, referentes ao domínio nutrição; a questão 4, sobre segurança; a questões 9, 10, e 11 do domínio medicamentos. Sobre as habilidades requeridas em cada uma delas, houve dificuldade de interpretação numérica, referente a multiplicação e divisão na questão 3, fração e decimais nas questões 4 e 10, múltiplas capacidades matemáticas na questão 18 , hierarquia numérica nas respostas 9 e 11. Para a pergunta sobre a oferta de suco à criança (questão 17), obteve-se $100 \%$ de acerto. Nesse caso, essa questão foi excluída para o cálculo de correlação e confiabilidade.

A avaliação da confiabilidade do instrumento na etapa do teste-reteste foi verificada pelo CCI, entre os resultados do teste e reteste, possibilitando avaliar a reprodutibilidade da escala. A consistência interna dos dados foi avaliada por meio da aplicação do coeficiente de Alfa Cronbach (tabela 3), cuja questão 14 obteve $100 \%$ de acerto e, em função disso, foi excluída do cálculo, mas não da escala.

Tabela 3. Coeficiente Alfa de Cronbach das questões da PHLAT, no teste-reteste, 2019

\begin{tabular}{lrrrrrrr}
\hline Questões & $\begin{array}{r}\text { Valores de } \\
\text { alpha }\end{array}$ & $\begin{array}{r}\text { Alpha } \\
\text { padronizado }\end{array}$ & G6* $^{\star}$ & $\begin{array}{r}\text { Média correlação } \\
\text { interitens }\end{array}$ & Erro padrão & Variância & Mediana \\
\hline Questão1.1 & 0.66 & 0.67 & 0.75 & 0.083 & 0.050 & 0.018 & 0.066 \\
Questão 2 & 0.66 & 0.67 & 0.76 & 0.086 & 0.049 & 0.019 & 0.073 \\
Questão 2.1 & 0.68 & 0.70 & 0.79 & 0.095 & 0.046 & 0.021 & 0.077 \\
Questão 2.2 & 0.68 & 0.70 & 0.79 & 0.094 & 0.046 & 0.022 & 0.074 \\
Questão 3.1 & 0.66 & 0.67 & 0.77 & 0.086 & 0.050 & 0.019 & 0.070 \\
Questão 3.2 & 0.68 & 0.69 & 0.79 & 0.093 & 0.047 & 0.021 & 0.078 \\
Questão 3.3 & 0.65 & 0.67 & 0.77 & 0.085 & 0.051 & 0.018 & 0.073 \\
Questão 4 & 0.68 & 0.69 & 0.79 & 0.094 & 0.047 & 0.022 & 0.073 \\
Questão 5 & 0.70 & 0.72 & 0.81 & 0.103 & 0.043 & 0.021 & 0.085 \\
Questão 6 & 0.70 & 0.71 & 0.80 & 0.102 & 0.043 & 0.021 & 0.085 \\
Questão 7 & 0.70 & 0.71 & 0.80 & 0.102 & 0.043 & 0.021 & 0.085 \\
Questão 8 & 0.68 & 0.69 & 0.79 & 0.093 & 0.047 & 0.021 & 0.073 \\
Questão 9 & 0.70 & 0.71 & 0.80 & 0.100 & 0.044 & 0.021 & 0.085 \\
Questão 10 & 0.66 & 0.68 & 0.78 & 0.088 & 0.049 & 0.021 & 0.066 \\
Questão 11 & 0.66 & 0.68 & 0.78 & 0.089 & 0.049 & 0.021 & 0.070 \\
\hline
\end{tabular}


Tabela 3. (cont.)

\begin{tabular}{lrrrrrrr}
\hline Questões & $\begin{array}{r}\text { Valores de } \\
\text { alpha }\end{array}$ & $\begin{array}{r}\text { Alpha } \\
\text { padronizado }\end{array}$ & G6* $^{*}$ & $\begin{array}{r}\text { Média correlação } \\
\text { interitens }\end{array}$ & Erro padrão & Variância & Mediana \\
\hline Questão 12 & 0.69 & 0.71 & 0.80 & 0.099 & 0.045 & 0.021 & 0.081 \\
Questão 13 & 0.71 & 0.72 & 0.80 & 0.104 & 0.042 & 0.020 & 0.085 \\
Questão 15 & 0.68 & 0.69 & 0.79 & 0.093 & 0.047 & 0.022 & 0.073 \\
Questão 16 & 0.69 & 0.70 & 0.80 & 0.097 & 0.046 & 0.022 & 0.078 \\
Questão 17 & 0.67 & 0.68 & 0.77 & 0.088 & 0.048 & 0.020 & 0.073 \\
Questão 18 & 0.71 & 0.72 & 0.80 & 0.102 & 0.043 & 0.021 & 0.085 \\
Questão 19 & 0.68 & 0.69 & 0.78 & 0.093 & 0.047 & 0.020 & 0.073 \\
Questão 20 & 0.69 & 0.71 & 0.80 & 0.099 & 0.045 & 0.021 & 0.078 \\
\hline
\end{tabular}

Fonte: Elaboração própria.

${ }^{\star} \mathrm{G} 6$ - Guttmans Lambda 6 teste de confiabilidade.

O coeficiente Alfa de Cronbach obtido foi de 0,69 , considerado valor aceitável20. Na tabela
4, apresenta-se o percentual de acertos das respostas de acordo com cada questão do teste.

Tabela 4. Percentual de acertos das respostas de acordo com as questões da PHLAT, no teste-reteste, 2019

\begin{tabular}{|c|c|c|c|c|}
\hline \multirow[b]{2}{*}{ Questões } & \multicolumn{2}{|c|}{ Respostas Teste } & \multicolumn{2}{|c|}{ Respostas Reteste } \\
\hline & Incorretas & Corretas & Incorretas & Corretas \\
\hline \multicolumn{5}{|c|}{$\begin{array}{l}1 \text { Usando as instruções oferecidas na embalagem de leite em pó 1, } \\
\text { quanto de água e de pó você deve colocar para fazer } 120 \mathrm{ml} \text { de leite? }\end{array}$} \\
\hline 1.1 Quantidade água utilizada: & $19 \%$ & $81 \%$ & $11 \%$ & $89 \%$ \\
\hline 1.2 Número de medidas colocadas: & $19 \%$ & $81 \%$ & $13 \%$ & $87 \%$ \\
\hline \multicolumn{5}{|c|}{$\begin{array}{l}2 \text { Usando as instruções oferecidas na embalagem de leite em pó } 2, \\
\text { quanto de água e de pó você colocaria para fazer } 210 \mathrm{ml} \text { de leite? }\end{array}$} \\
\hline 2.1 Quantidade de água utilizada: & $11 \%$ & $89 \%$ & $5 \%$ & $95 \%$ \\
\hline 2.2 Número de medidas colocadas: & $9 \%$ & $91 \%$ & $10 \%$ & $90 \%$ \\
\hline \multicolumn{5}{|c|}{$\begin{array}{l}3 \text { Seu bebê tem diarreia, e o pediatra recomenda que você dê uma } \\
\text { mamadeira de } 240 \mathrm{ml} \text {, misturando metade de leite e metade de soro } \\
\text { para reidratação oral. Como você prepararia essa mamadeira com o } \\
\text { leite em pó 1? }\end{array}$} \\
\hline 3.1 Quantidade de água utilizada: & $32 \%$ & $68 \%$ & $27 \%$ & $73 \%$ \\
\hline 3.2 Número de medidas colocadas: & $51 \%$ & $49 \%$ & $48 \%$ & $52 \%$ \\
\hline 3.3 Quantidade de soro utilizada: & $34 \%$ & $66 \%$ & $28 \%$ & $72 \%$ \\
\hline
\end{tabular}

4 Você é informado pelo pediatra do seu bebê para levá-lo a um serviço de saúde se ele tiver uma temperatura de $38^{\circ} \mathrm{C}$ ou maior. No termômetro, está marcando a seguinte temperatura: $37,8^{\circ} \mathrm{C}$.

Você deveria levar sua criança para avaliação no serviço de saúde?

$57 \% \quad 43 \% \quad 55 \% \quad 45 \%$

5 Vamos dizer que sua criança de 10 meses pesa 10.400 gramas e tem altura normal para a idade. Usando a tabela sobre o uso de assentos para crianças, qual assento para o carro você deve escolher para seu filho?
a) Bebê conforto, virado para trás, no banco traseiro
$25 \% \quad 75 \% \quad 26 \% \quad 74 \%$
b) Bebê conforto, virado para a frente, no banco traseiro

$0 \% \quad 0 \% \quad 0 \% \quad 0 \%$


Tabela 4. (cont.)

\begin{tabular}{|c|c|c|c|c|}
\hline \multirow[b]{2}{*}{ Questões } & \multicolumn{2}{|c|}{ Respostas Teste } & \multicolumn{2}{|c|}{ Respostas Reteste } \\
\hline & Incorretas & Corretas & Incorretas & Corretas \\
\hline c) Cadeira de segurança, virada para trás, no banco traseiro & $0 \%$ & $0 \%$ & $0 \%$ & $0 \%$ \\
\hline d) Cadeira de segurança, virada para a frente, no banco traseiro & $0 \%$ & $0 \%$ & $0 \%$ & $0 \%$ \\
\hline $\begin{array}{l}6 \text { Na consulta de acompanhamento de } 2 \text { meses do seu bebê, o } \\
\text { médico lhe diz que, de acordo com a curva de crescimento infa } \\
\text { ele está no percentil } 25 \text { de peso. } 0 \text { que esse percentil significa }\end{array}$ & & & & \\
\hline favor, veja a curva de crescimento exibida. & $38 \%$ & $62 \%$ & $33 \%$ & $67 \%$ \\
\hline $\begin{array}{l}7 \text { Se seu bebê de } 7 \text { meses pesa } 8 \text { quilos e está com febre, quar } \\
\text { remédio para febre você deve dar a ele? Usando a Tabela de } \\
\text { Dosagem do medicamento exibida, indique a quantidade de g } \\
\text { remédio que você deve dar ao seu filho. Decida a dose com ba }\end{array}$ & & & & \\
\hline peso dele. & $32 \%$ & $68 \%$ & $40 \%$ & $60 \%$ \\
\hline $\begin{array}{l}8 \text { Examinando as bulas dos dois tipos de medicamentos infant } \\
\text { febre exibidas, de qual deles você precisaria usar um número } \\
\text { de gotas, para tratar a febre do seu bebê? }\end{array}$ & & & & \\
\hline a) Ibuprofeno $50 \mathrm{mg}$ & $0 \%$ & $0 \%$ & $0 \%$ & $0 \%$ \\
\hline b) Ibuprofeno $100 \mathrm{mg}$ & $32 \%$ & $68 \%$ & $34 \%$ & $66 \%$ \\
\hline $\begin{array}{l}9 \text { Seu bebê de } 3 \text { meses pesa } 5 \text { quilos e está com febre e você c } \\
\text { remédio para febre, em gotas. Usando a caixa como referência } \\
\text { daria o medicamento ao seu bebê? }\end{array}$ & & & & \\
\hline ( ) $\operatorname{Sim}$ & $0 \%$ & $0 \%$ & $0 \%$ & $0 \%$ \\
\hline ( ) Eu ligaria para o pediatra ou levaria ao serviço de saúde & $57 \%$ & $43 \%$ & $55 \%$ & $45 \%$ \\
\hline ( ) Não & $0 \%$ & $0 \%$ & $0 \%$ & $0 \%$ \\
\hline
\end{tabular}

10 Se você estiver usando remédio infantil para tratar a febre do seu filho, e seu médico recomendar que você dê apenas $1 / 2$ colher de chá do medicamento, quantos mililitros $(\mathrm{ml})$ você precisa dar? Você pode consultar a tabela exibida.

11 Seu sobrinho de 3 anos e 16 quilos vem visitá-los e, de repente, ele está com febre. Para tratá-la, você decide dar-lhe o recomendado na bula do remédio infantil para febre de $2,5 \mathrm{ml}$. Quanto você deve dar a ele?

\begin{tabular}{llllr} 
a) $1 / 2$ colher de chá & $61 \%$ & $39 \%$ & $58 \%$ & $42 \%$ \\
b) 1 colher de chá & $0 \%$ & $0 \%$ & $0 \%$ & $0 \%$ \\
c) $11 / 2$ colher de chá & $0 \%$ & $0 \%$ & $0 \%$ & $0 \%$ \\
d) 1 colher de sopa & $0 \%$ & $0 \%$ & $0 \%$ & $0 \%$ \\
\hline
\end{tabular}

120 seu médico lhe dá a seguinte lista de alimentos para evitar dar ao seu bebê:

- Leite

- Amendoim,

- Claras de ovos castanhas, nozes

- Uvas

- Peixe e marisco

- Pipoca

- Cenouras cruas

- Cachorro-quente

Depois de ler a lista de ingredientes do biscoito entregue, você daria isso para o seu bebê de 10 meses?

\begin{tabular}{lrrrr} 
( ) $\operatorname{Sim}$ & $0 \%$ & $0 \%$ & $0 \%$ & $0 \%$ \\
$($ ) Não & $31 \%$ & $69 \%$ & $27 \%$ & $73 \%$ \\
\hline
\end{tabular}


Tabela 4. (cont.)

\begin{tabular}{|c|c|c|c|c|}
\hline \multirow[b]{2}{*}{ Questões } & \multicolumn{2}{|c|}{ Respostas Teste } & \multicolumn{2}{|c|}{ Respostas Reteste } \\
\hline & Incorretas & Corretas & Incorretas & Corretas \\
\hline \multicolumn{5}{|c|}{$\begin{array}{l}13 \text { Aos } 6 \text { meses de idade, seu bebê tem uma chance maior de } \\
\text { pegar resfriados e outras infecções. Tomando como exemplo } \\
\text { o paracetamol gotas entregue, decida se você usaria esse } \\
\text { medicamento para seu filho e quanto você daria. }\end{array}$} \\
\hline ( ) Sim - eu daria ___ (coloque a quantidade) & $0 \%$ & $0 \%$ & $0 \%$ & $0 \%$ \\
\hline ( ) Sim - mas eu perguntaria ao pediatra primeiro & $40 \%$ & $60 \%$ & $42 \%$ & $58 \%$ \\
\hline ( ) Não - eu não daria o medicamento para meu filho & $0 \%$ & $0 \%$ & $0 \%$ & $0 \%$ \\
\hline \multicolumn{5}{|c|}{$\begin{array}{l}14 \text { De acordo com as informações na caixa do medicamento } \\
\text { oferecida, que sintomas esta medicação NÃO ajuda a aliviar. }\end{array}$} \\
\hline a) congestão nasal & $0 \%$ & $0 \%$ & $0 \%$ & $0 \%$ \\
\hline b) Vômito & $0 \%$ & $0 \%$ & $0 \%$ & $0 \%$ \\
\hline c) Febre & $0 \%$ & $100 \%$ & $0 \%$ & $100 \%$ \\
\hline d) Tosse & $0 \%$ & $0 \%$ & $0 \%$ & $0 \%$ \\
\hline
\end{tabular}

15 Seu bebê tem 1 ano de idade, pesa 8 quilos e está resfriado e com febre. Você dá a ele a quantidade de gotas de paracetamol que sempre usa, mas, uma hora depois, ele ainda está com febre. Você também tem um frasco de dipirona. $O$ que você deve fazer, dar o outro medicamento ou esperar?

\begin{tabular}{lrrrr} 
a) Dar__ml/gotas de dipirona & $0 \%$ & $0 \%$ & $0 \%$ & $0 \%$ \\
b) Esperar, porque & $24 \%$ & $76 \%$ & $27 \%$ & $73 \%$ \\
\hline
\end{tabular}

16 Seu bebê tem uma infecção no ouvido, e o médico receitou amoxicilina 3 vezes ao dia (ver frasco). Usando a seringa/copo, demonstre como você administraria a dose prescrita de $5 \mathrm{ml}$.

\begin{tabular}{lrrrr} 
a) Demonstrou corretamente & $10 \%$ & $90 \%$ & $6 \%$ & $94 \%$ \\
b) Demonstrou incorretamente & $0 \%$ & $0 \%$ & $0 \%$ & $0 \%$ \\
\hline
\end{tabular}

17 Um nutricionista diz-Ihe para dar ao seu bebê, com mais de 6 meses, não mais que $50 \mathrm{ml}$ de suco por vez. $200 \mathrm{ml}$ de suco dará para quantas vezes?

$13 \% \quad 87 \% \quad 15 \% \quad 85 \%$

18 Bebidas industrializadas adoçadas possuem quantidades elevadas de açúcar e baixo teor de nutrientes importantes para manutenção da saúde. Deve-se dar preferência a sucos naturais com $100 \%$ de frutas ou vegetais. Os sucos prontos devem especificar no rótulo quanto de açúcar, vitaminas, proteínas, sódio e outros componentes contém. Com base nessa informação, analise o rótulo com os Dados Nutricionais, do suco demonstrado, e decida se poderia ser dado ao seu filho?

\begin{tabular}{|c|c|c|c|c|}
\hline ( ) $\operatorname{sim}$ & $0 \%$ & $0 \%$ & $0 \%$ & $0 \%$ \\
\hline ( ) Não & $46 \%$ & $54 \%$ & $42 \%$ & $58 \%$ \\
\hline
\end{tabular}

19 Nos primeiros 3 dias de aleitamento materno, o peito fica inchado e dolorido. De acordo com este folheto, quanto tempo vai levar para melhorar?

$18 \% \quad 82 \% \quad 16 \% \quad 84 \%$

20 Você não tem certeza se o seu bebê está recebendo leite suficiente, uma vez que demora cerca de 15 minutos para se alimentar em ambos os seios. De acordo com este folheto, isto é:

\begin{tabular}{lrrrr} 
a) normal & $12 \%$ & $88 \%$ & $13 \%$ & $87 \%$ \\
b) mais que o normal & $0 \%$ & $0 \%$ & $0 \%$ & $0 \%$ \\
c) menos que o normal & $0 \%$ & $0 \%$ & $0 \%$ & $0 \%$ \\
\hline
\end{tabular}

Fonte: Elaboração própria. 
No teste, as questões que exibiram o percentual de acertos das respostas que ficaram abaixo de $50 \%$, referentes ao domínio nutrição, foram as 3.2, 4 (no pré-teste $48 \%$ e no teste 43\%); sobre segurança, a questão 9 (no pré-teste $6 \%$, no teste $43 \%$ ), no domínio medicamentos, a questão 10 (pré-teste $48 \%$ e no teste $37 \%$ ) e questão 11 (no pré-teste $42 \%$, no teste $39 \%$ ). Sobre as habilidades requeridas em cada uma delas, houve pouca capacidade de interpretação numérica, referente a multiplicação e divisão na questão 3 , fração e decimais nas questões 4 e 10, hierarquia numérica nas respostas 9 e 11. Para a pergunta sobre que sintomas esta medicação NÃO ajuda a aliviar (questão 14), obteve-se $100 \%$ de acerto.

Os dados de alfa de cada questão estão apresentados na tabela 5 , a seguir.

Tabela 5. Comparação do Alfa de Cronbach entre o pré-teste e teste, 2019

\begin{tabular}{|c|c|c|}
\hline Questões & Alpha pré-teste & Alpha teste \\
\hline Questão1.1 & 0.71 & 0.66 \\
\hline Questão 2 & 0.70 & 0.66 \\
\hline Questão 2.1 & 0.72 & 0.68 \\
\hline Questão 2.2 & 0.72 & 0.68 \\
\hline Questão 3.1 & 0.70 & 0.66 \\
\hline Questão 3.2 & 0.71 & 0.68 \\
\hline Questão 3.3 & 0.69 & 0.65 \\
\hline Questão 4 & 0.71 & 0.68 \\
\hline Questão 5 & 0.72 & 0.70 \\
\hline Questão 6 & 0.72 & 0.70 \\
\hline Questão 7 & 0.74 & 0.70 \\
\hline Questão 8 & 0.72 & 0.68 \\
\hline Questão 9 & 0.73 & 0.70 \\
\hline Questão 10 & 0.72 & 0.66 \\
\hline Questão 11 & 0.69 & 0.66 \\
\hline Questão 12 & 0.73 & 0.69 \\
\hline Questão 13 & 0.73 & 0.72 \\
\hline Questão 14 & 0.73 & - \\
\hline Questão 15 & 0.73 & 0.68 \\
\hline Questão 16 & 0.73 & 0.69 \\
\hline Questão 17 & - & 0.67 \\
\hline Questão 18 & 0.75 & 0.71 \\
\hline Questão 19 & 0.71 & 0.68 \\
\hline Questão 20 & 0.71 & 0.69 \\
\hline
\end{tabular}

Fonte: Elaboração própria.

A avaliação da confiabilidade do instru- intervalo de confiança de $95 \%$. mento analisada pelo CCI foi de 0,865 com 


\section{Discussão}

Sobre os dados de validação para o português do instrumento PHLAT, tanto no pré-teste quanto no teste e reteste, evidenciou-se que as questões obtiveram coeficiente Alfa de Cronbach de 0,73 e 0,69, respectivamente, considerado substancial21 e comparável a confiabilidade do instrumento original, o qual foi avaliado por meio de testes de consistência interna com o Kuder-Richardson apresentando valor de KR-20 igual a 0,76 ${ }^{16}$.

As dificuldades e as limitações são inerentes à adaptação e à validação de instrumentos de outro país de origem, pois o país-alvo tem significativas diferenças culturais e de linguagem, tornando as modificações inevitáveis ${ }^{15}$, sendo necessário adaptação de itens na língua portuguesa, que não eram adequados para a realidade brasileira. Contudo, preservou-se a originalidade do instrumento de origem, certificada na retrotradução, mesmo que tenham sido geradas diferenças semânticas ou conceituais entre a escala original e a versão de síntese alcançada ${ }^{19}$, para adequação ao público brasileiro.

Outra limitação do estudo apresenta-se sob a forma de inexistência de instrumentos que mensurem o LFS de pais/cuidadores de crianças, visto que estudos sobre o tema ainda são limitados no cenário internacional e no Brasil. Tal fato assume importância relevante na medida em que o grupo infantil é público assíduo na atenção primária, principalmente em busca de cuidado às doenças respiratórias, que acometem crianças de modo prevalente no País e influenciam na hospitalização por causas evitáveis pela atenção primária ${ }^{22}$.

Preocupam os dados evidenciados por este estudo (tabela 4), os quais apontam que: $43 \%$ dos cuidadores conseguiram interpretar um termômetro para decidir se a temperatura indicada seria motivo para levar ou não seu filho ao pediatra; $68 \%$ conseguiram interpretar, após o fornecimento da dosagem/peso, a quantidade correta de administração de um medicamento; $57 \%$ comprariam e administrariam uma medicação ao filho sem indicação do pediatra; $62 \%$ souberam interpretar se o percentil na curva de crescimento oferecida estava adequado para o peso/idade; $63 \%$ e $61 \%$ (questões 10 e 11) não conseguiram interpretar e transformar mililitros (ml) em medidas de colher para administrar o medicamento; $54 \%$ apontaram que dariam sucos industrializados para seus filhos.

Ainda, o percentual dos cuidadores que conseguiram preparar uma mamadeira de $240 \mathrm{ml}$ fracionada com soro de reidratação oral foi de 61\% (tabela 4-Teste). Grande parte dos cuidadores entrevistados (88\%), após ler o folheto de aleitamento materno, responderam que o tempo de intervalo entre mamadas demonstrado era normal para a amamentação. Em comparação com os valores do estudo original ${ }^{16}, 69 \%$ foram capazes de ler corretamente um termômetro para determinar se deveriam chamar o pediatra ou não; $53 \%$ foram capazes de determinar a dose adequada do medicamento em gotas. Somente $64 \%$ puderam determinar corretamente se forneceriam um suco industrializado, $51 \%$ puderam interpretar o percentil de uma curva de crescimento. Poucos participantes (18\%), depois de ler um guia sobre amamentação, conseguiram determinar quanto o tempo gasto na amamentação foi menor que o normal, semelhante a estudo sobre o tema ${ }^{16}$.

Os resultados do PHLAT apontam inúmeros desafios que os cuidadores enfrentam ao tentar fornecer cuidados diários apropriados, relacionados com a saúde infantil. Evidencia que os cuidadores, frequentemente, têm sido incapazes de entender os rótulos de nutrição e medicação, folhetos simples de saúde infantil e recomendações básicas sobre o cuidado infantil. Muitos também não conseguiram misturar fórmulas infantis ou medicação adequadamente ${ }^{16}$.

Estudo com população de mães adolescentes $^{\mathbf{2 3}}$, mas que pode ser ampliado para a população geral, demonstrou a importância do letramento na saúde da criança em suas diversas especificidades, quanto à comunicação sobre saúde e à vulnerabilidade, que necessitam de informações claras, precisas e 
acessíveis sobre saúde para promover a própria saúde e a do bebê, justificando, dessa forma, a escolha pela adaptação e validação dessa escala e para esse público, que não dispunha de um instrumento de mensuração do LFS adequado às condições brasileiras.

\section{Conclusões}

O PLHAT versão brasileira apresentou-se como um instrumento confiável para mensurar o LFS do cuidador em relação à indicação terapêutica do profissional de saúde para seu filho, possibilitando avaliar a relação entre o LS e as famílias usuárias do Sistema Único de Saúde no momento do atendimento de suas crianças na unidade de atenção primária. Sua importância reside em que, se o familiar cuidador não compreende a terapêutica proposta, pode não a implementar ou fazê-la de modo parcial, levando ao agravamento do quadro de saúde da criança e, consequentemente, à hospitalização por condições que seriam passíveis de serem resolvidas no âmbito da atenção primária à saúde.

O PHLAT versão brasileira demonstra grande relevância na utilização cotidiana da atenção primária, pois pode ser aplicado para identificação das vulnerabilidades de compreensão e comunicação que acometem a criança e as famílias que necessitam de maiores e melhores informações no contexto do cuidado infantil. Os achados deste estudo indicam a importância da comunicação clara em saúde, focada nas habilidades básicas necessárias à saúde da criança, bem como um direcionamento dos profissionais para melhorar a comunicação com os cuidadores, incluindo materiais interativos de educação e saúde de fácil compreensão.

Percebeu-se a necessidade de melhorar o entendimento da informação sobre saúde infantil, envidando esforços que visam aprimorar o atendimento, investindo em mais tempo de duração das consultas e em compartilhamento de saberes profissionais durante os atendimentos, incluindo-se nas consultas os enfermeiros, cujo potencial de educação em saúde tem grande relevância nesse processo do cuidado.

\section{Colaboradores}

Simch FBL (0000-0002-4722-4891)* e Toso BRGO (0000-0001-7366-077X)* contribuíram para concepção do projeto, condução do estudo, coleta de dados, análise de dados, redação e aprovação final do manuscrito. Vieira CS (0000-0002-0900-4660)* contribuiu para condução do estudo, coleta de dados, análise de dados, redação e aprovação final do manuscrito. Santos MB (0000-0001-8826-8930)* contribuiu para análise de dados, redação e aprovação final do manuscrito. 


\section{Referências}

1. Soares M. Letramento: Um Tema em Três Gêneros. Belo Horizonte: Autêntica; 2001.

2. Coelho MAM, Sampaio HAC, Passamai MPB, et al. Functional health literacy and healthy eating: Understanding the brazilian food guide recommendations. Rev Nutr [internet]. 2014 [acesso em 2018 abr 30]; 27(6):1-10. Disponível em: http:// www.scielo.br/scielo.php?script=sci_arttext\&pid $=$ S1415-52732014000600715.

3. Santos JEM, Brasil VV, Moraesi KL, et al. Legibilidade de prospecto facilitador e letramento em saúde de indivíduos com marcapasso. Rev Bras Enferm [internet]. 2017 [acesso em 2018 maio 15]; 70(3):1-7. Disponível em: http://www.scielo.br/pdf/reben/v70n3/ pt_0034-7167-reben-70-03-0633.pdf.

4. Santos L, Mansur HN, Paiva TFPS, et al. Letramento em saúde: importância da avaliação em nefrologia. J Bras Nefrol [internet]. 2012 [acesso em 2018 abr 29]; 34(3):1-10. Disponível em: http://www.scielo.br/pdf/ jbn/v34n3/v34n3al4.pdf.

5. Passamai MPB, Sampaio HAC, Dias AMI, et al. Letramento funcional em saúde: reflexões e conceitos. Interface [internet]. 2012 [acesso em 2018 abr 29]; 16(4):1-14. Disponível em: http://www.scielo.br/pdf/ icse/v16n41/aop2812.pdf.

6. Santos MIPO, Portella MR. Condições do letramento funcional em saúde de um grupo de idosos diabéticos. Rev Bras Enferm [internet]. 2016 [acesso em 2018 jul 9]; 69(1):1-9. Disponível em: http://www.scielo.br/pdf/reben/v69nl/0034-7167-reben-69-01-0156.pdf.

7. Santos MIPO, Portella MR, Scortegagna HM, et al. Letramento funcional em saúde na perspectiva da Enfermagem Gerontológica: revisão integrativa da literatura. Rev Bras Geriatr Gerontol [internet]. 2015 [acesso em 2018 abr 30]; 18(3):1-14. Disponível em: http://www.scielo.br/pdf/rbgg/v18n3/1809-9823rbgg-18-03-00651.pdf.
8. Marques SR, Lemos SMA. Instrumentos de avaliação do letramento em saúde: revisão sistemática. Rev Audiol Commun Res [internet]. 2017 [acesso em $2019 \mathrm{dez}$ 4]; 22(e1757):1-12. Disponível em: http://www.scielo. br/pdf/acr/v22/2317-6431-acr-2317-6431-2016-1757. pdf.

9. Parker RM, Baker DW, Williams MV, et al. The test of functional health literacy in adults: a new instrument for measuring patients' literacy skills. J Gen Intern Med [internet]. 1995 [acesso em 2018 out 23]; 10(10):1-55. Disponível em: https://www.ncbi.nlm. nih.gov/pubmed/8576769.

10. Davis TC, Long SW, Jackson RH, et al. Rapid estimate of adult literacy in medicine: a shortened screening instrument. J Fam Med [internet]. 1993 [acesso em 2018 out 23]; 25(6):1-5. Disponível em: https://www. ncbi.nlm.nih.gov/pubmed/8349060.

11. Apolinario D, Braga RCOP, Magaldi RM, et al. Short Assessment of Health Literacy for Portuguese-speaking Adults. Rev Saúde Pública [internet]. 2012 [acesso em 2018 out 23]; 46(4):1-10. Disponível em: http:// www.scielo.br/pdf/rsp/v46n4/ao3816.pdf.

12. Baker DW, Williams MV, Parker RM, et al. Development of a brief test to measure functional health literacy. Patient Educ Couns [internet]. 1999 [acesso em 2018 out 23]; 38(1):1-10. Disponível em: https:// www.ncbi.nlm.nih.gov/pubmed/14528569.

13. Carthery-goulart MT, Anghinah R, Areza-fegyveres $\mathrm{R}$, et al. Performance of a Brazilian population on the test of functional health literacy in adults. Rev Saúde Pública [internet]. 2009 [acesso em 2018 maio 14]; 43(4):1-8. Disponível em: http://www.scielo.br/pdf/ rsp/v43n4/124.pdf.

14. Quemelo PRV, Milani D, Bento VF, et al. Literacia em saúde: tradução e validação de instrumento para pesquisa em promoção da saúde no Brasil. Cad. Saúde Pública [internet]. 2017 [acesso em $2019 \mathrm{dez}$ 17]; 33(2):e00179715. Disponível em: http://www.scielo.br/pdf/csp/v33n2/16784464-csp-33-02-e00179715.pdf. 
15. Maragno CAD, Mengue SS, Moraes CG, et al. Teste de letramento em saúde em português para adultos. Rev Bras Epidemol [internet]. 2019 [acesso em 2019 dez 17]; 22(E190025):1-12. Disponível em: http:// www.scielo.br/pdf/rbepid/v22/1980-5497-rbepid-22-e190025.pdf.

16. Kumar D, Sanders L, Perrin E, et al. Parental understanding of infant health information: Health literacy, numeracy, and the Parental Health Literacy Activities Test (PHLAT). Acad Pediatr [internet]. 2010 [acesso em 2018 out 23]; 10(5):1-8. Disponível em: https:// www.ncbi.nlm.nih.gov/pubmed/20674532.

17. Beaton DE, Bombardier C, Guillemin F, et al. Guidelines for the process of cross-cultural adaptation of self-report measures. Spine [internet]. 2000 [acesso em 2020 ago 24]; 25(24):1-6. Disponível em: https:// lab.research.sickkids.ca/pscoreprogram/wp-content/ uploads/sites/72/2017/12/Beaton2000-GuidelinesCrossCulturalAdaptation.pdf.

18. Souza AC, Alexandre NMC, Guirardello EB. Propriedades psicométricas na avaliação de instrumentos: avaliação da confiabilidade e da validade. Epidemiol. Serv. Saúde [internet]. 2017 [acesso em 2020 jun 4]; 26(3):649-659. Disponível em: https://www.scielo. br/pdf/ress/v26n3/2237-9622-ress-26-03-00649.pdf.

19. Pernambuco L, Espelt A, Magalhaes-Junior HV, et al. Recomendações para elaboração, tradução, adapta- ção transcultural e processo de validação de testes em Fonoaudiologia. CoDAS [internet]. 2017 [acesso em 2019 jul 9]; 29(3):e20160217. Disponível em: http:// www.scielo.br/pdf/codas/v29n3/2317-1782-codas29-3-e20160217.pdf.

20. Hair JF, Black WC, Babin BJ, et al. Análise multivariada de dados. 6. ed. Porto Alegre: Bookman; 2009.

21. Viera S. Introdução à bioestatística. Rio de Janeiro: Elsevier; 2016.

22. Toso BRGO, Ross C, Sotti CW, et al. Profile of children hospitalizations by primary care sensitive Conditions. Rev Acta Scientiarum Health Sciences [internet]. 2016 [acesso em 2018 abr 29]; 38(2):1-8. Disponível em: http://periodicos.uem.br/ojs/index.php/ActaSciHealthSci/article/view/29422/pdf.

23. Logsdon MC, Davis DW, Ratterman R, et al. Acceptability and initial efficacy of education for teen mothers. MCN Am J Matern Child Nurs [internet]. 2015 [acesso em 2018 nov 20]; 40(3):1-7. Disponível em: https://www.ncbi.nlm.nih.gov/pubmed/25919212.

Recebido em 29/02/2020

Aprovado em 28/08/2020

Conflito de interesses: inexistente

Suporte financeiro: não houve 